\title{
Solar powered model vehicle races
}

\section{Nazmi Yılmaz, Ali Serpengüzel}

Nazmi Yılmaz, Ali Serpengüzel, "Solar powered model vehicle races," Proc. SPIE 9188, Optics Education and Outreach III, 91880 S (15 September 2014); doi: $10.1117 / 12.2065529$

EDIE Event: SPIE Optical Engineering + Applications, 2014, San Diego, California, SPIE. United States 


\title{
Solar Powered Model Vehicle Races
}

\author{
Nazmi Y1lmaz and Ali Serpengüzel \\ Koç University, Physics Department, \\ Rumelifeneri Yolu, Sarıyer, Istanbul 34450 Turkey
}

\begin{abstract}
Koç University SPIE student chapter have been organizing the solar powered model vehicle race and reaching out to K12 students. The solar powered model vehicle race for car, boat, blimp, all solar panel boat, submarine, underwater rower, amphibian, and glider have been successfully organized.
\end{abstract}

Keywords: K-12 students; model vehicle; optics education; photonics outreach; photovoltaic; science, technologyengineering, and mathematics (STEM); solar power; solar powered model vehicle race (SOPMOVER).

\section{PURPOSE OF THE EVENT}

The events started to promote optics and photonics in special and the science, technology-engineering, and mathematics (STEM) in general to K-12 students in Istanbul in special, and Turkey in general. To attract the interest of the K-12 students, we aimed to make the photonic platform mobile, as in the case of aerospace photovoltaics platforms such as blimps, satellites and space stations.

Given Turkey's geographical latitude and technology base, photovoltaics seemed like an appropriate choice. So on earth, in Turkey, at K-12 level, the solar powered model vehicle race (SOPMOVER) is a great way to attract bright young minds into the exciting fields of optical science and photonics engineering. The SOPMOVER car 2006, boat 2007, blimp 2008, all solar panel boat 2009, submarine 2010, underwater rower 2011, amphibian 2012, and glider 2013 have been successfully organized. Among these races, the blimp, the all solar panel boat, the submarine, the underwater rover and the amphibian races are worldwide firsts to the best of our knowledge. During the SOPMOVERS, we have seen ingenious approaches to solve various engineering problems from K-12 students and their mentors. With appropriate guidance and promotion SOPMOVER can turn into another K-12 STEM event like the FIRST LEGO League [1] and the world solar challenge [2].

\section{FEASIBILITY STUDIES}

Before the year's race can be undertaken, one has to make sure the concept works. Therefore, we ask high school students, who participate to the Koç University Summer Research Program to build the next years SOPMOVER vehicle. We provide them with solar panels and remote controlled battery operated vehicles, they can use as a base for their solar powered model vehicle.

The idea is simple: "take out the battery cells, replace them with solar cells, and make sure the vehicle still works." In the meantime, the students get introduced to various STEM concepts, such as mechanical, hydraulic, electrical, and optical design, manufacturing, measurement, testing, optimization, and careful laboratory notebook keeping. These scientific and technical activities give the students a glimpse of what the theoretical and practical aspects of STEM are all about. 


\section{SOLAR POWERED MODEL VEHICLE RACES}

The SOPMOVER car was organized at Koç University Square in 2006. This was the first race to promote optics and photonics and with young kids participating.
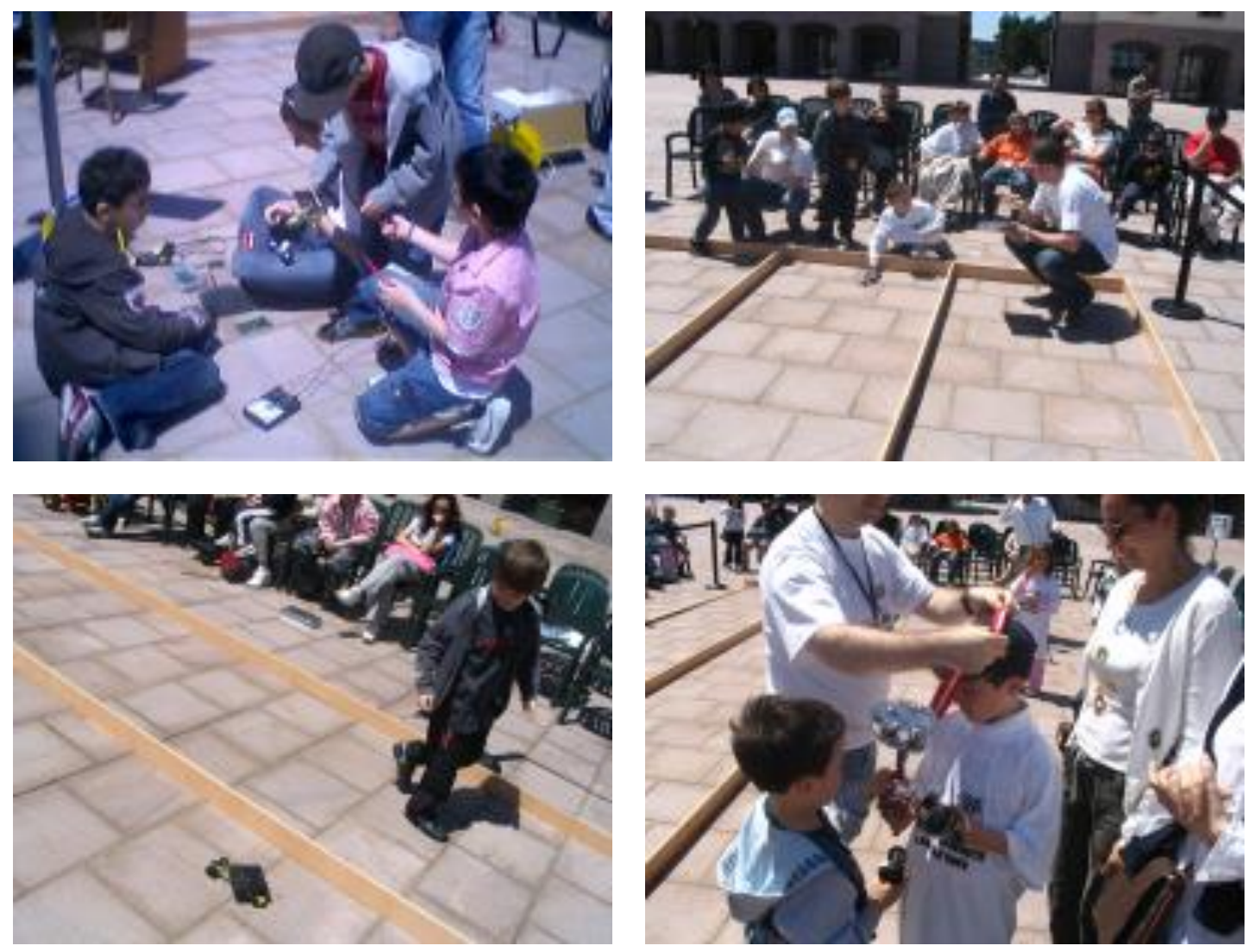

Figure 1. Photos from the SOPMOVER car organized in 2006.

The SOPMOVER boat was organized in 2007 at the Darüşşafaka Gymnasium open swimming pool. This was the second race to promote optics and photonics with young kids participating.
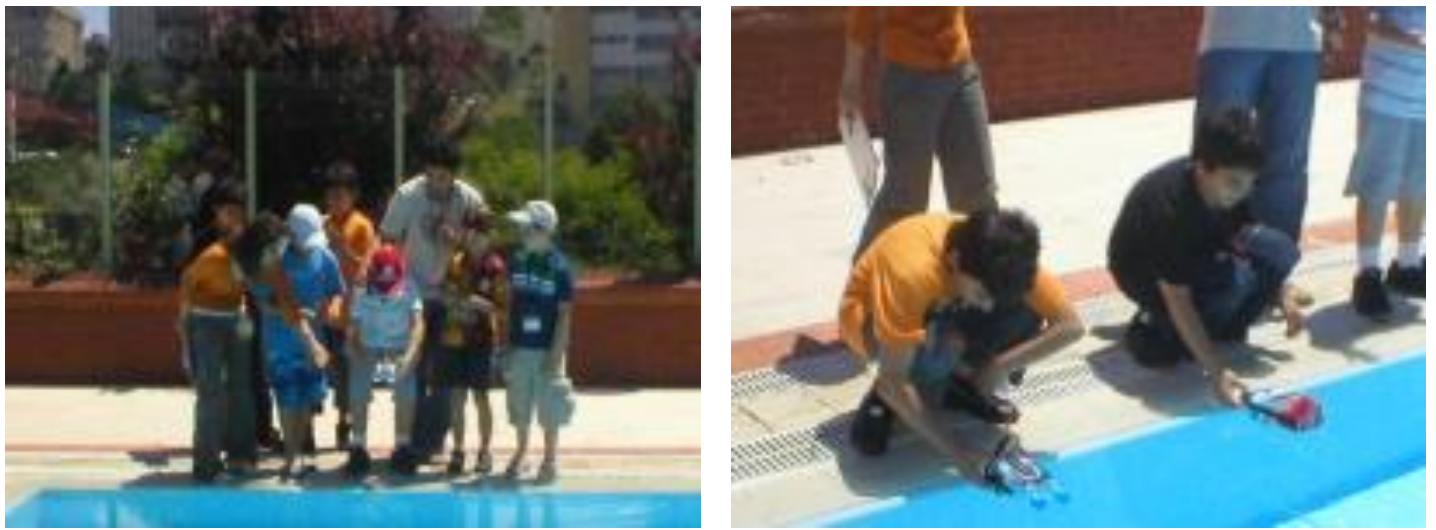

Figure 2(a). Photos from the SOPMOVER boat organized in 2007. 


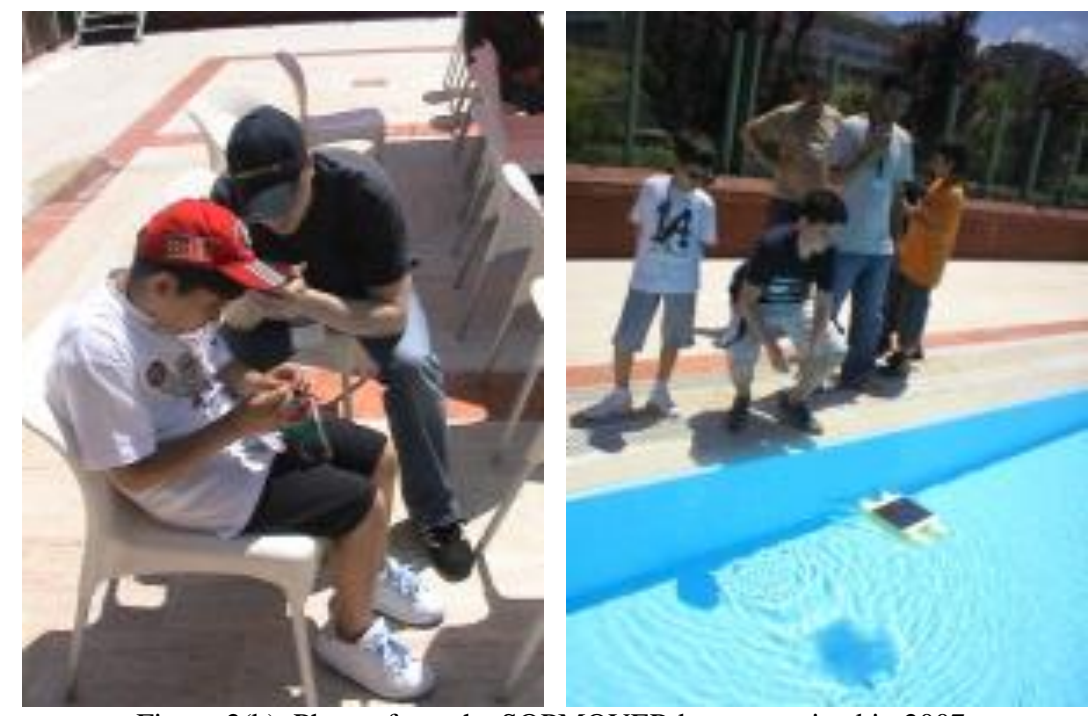

Figure 2(b). Photos from the SOPMOVER boat organized in 2007.

The SOPMOVER blimp was organized in 2008 in nylon covered Koç University tennis court to block the wind from pushing the blimps. This race was the third in the series and the age group of the participants was older.
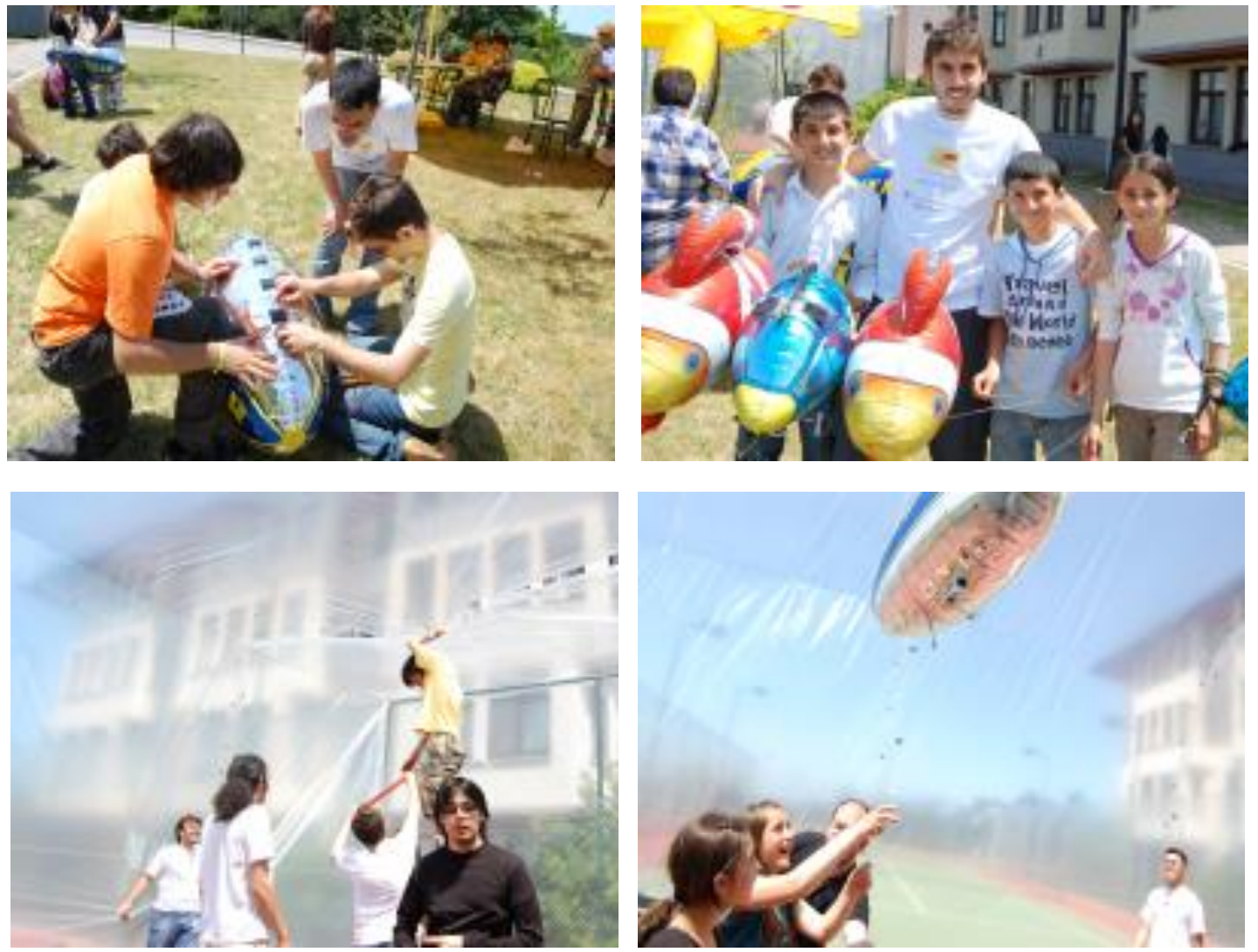

Figure 3. Photos from the SOPMOVER blimp organized in 2008.

The SOPMOVER all solar panel boat was organized in 2009 at the Koç University open swimming pool. The idea was that the solar panels covered all the surfaces of the boats. This race was the fourth in the series and high school students started to participate. 

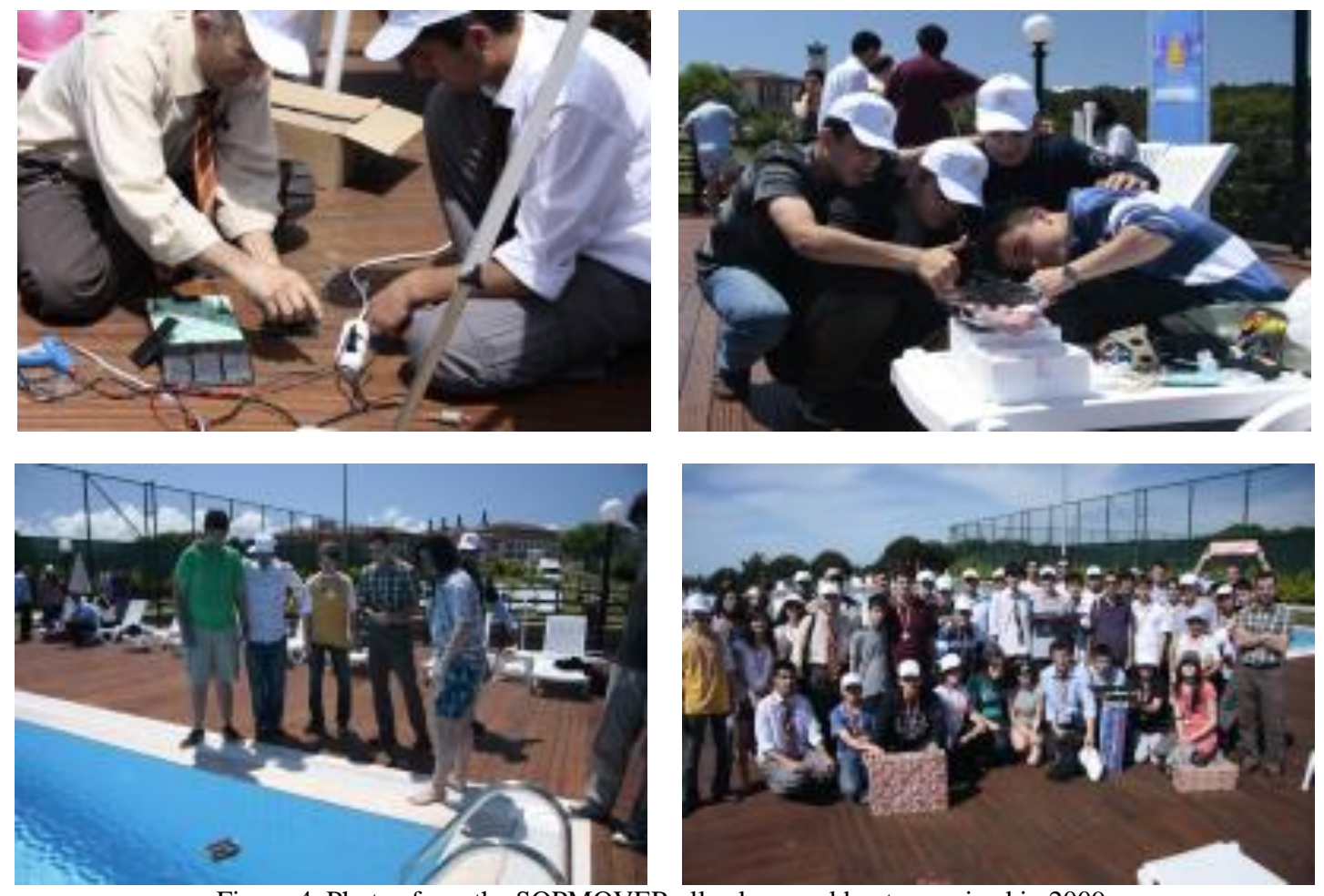

Figure 4. Photos from the SOPMOVER all solar panel boat organized in 2009.

The SOPMOVER submarine was organized in 2010 at the Koç University open swimming pool. This race was the fifth in the series with high school students participating.
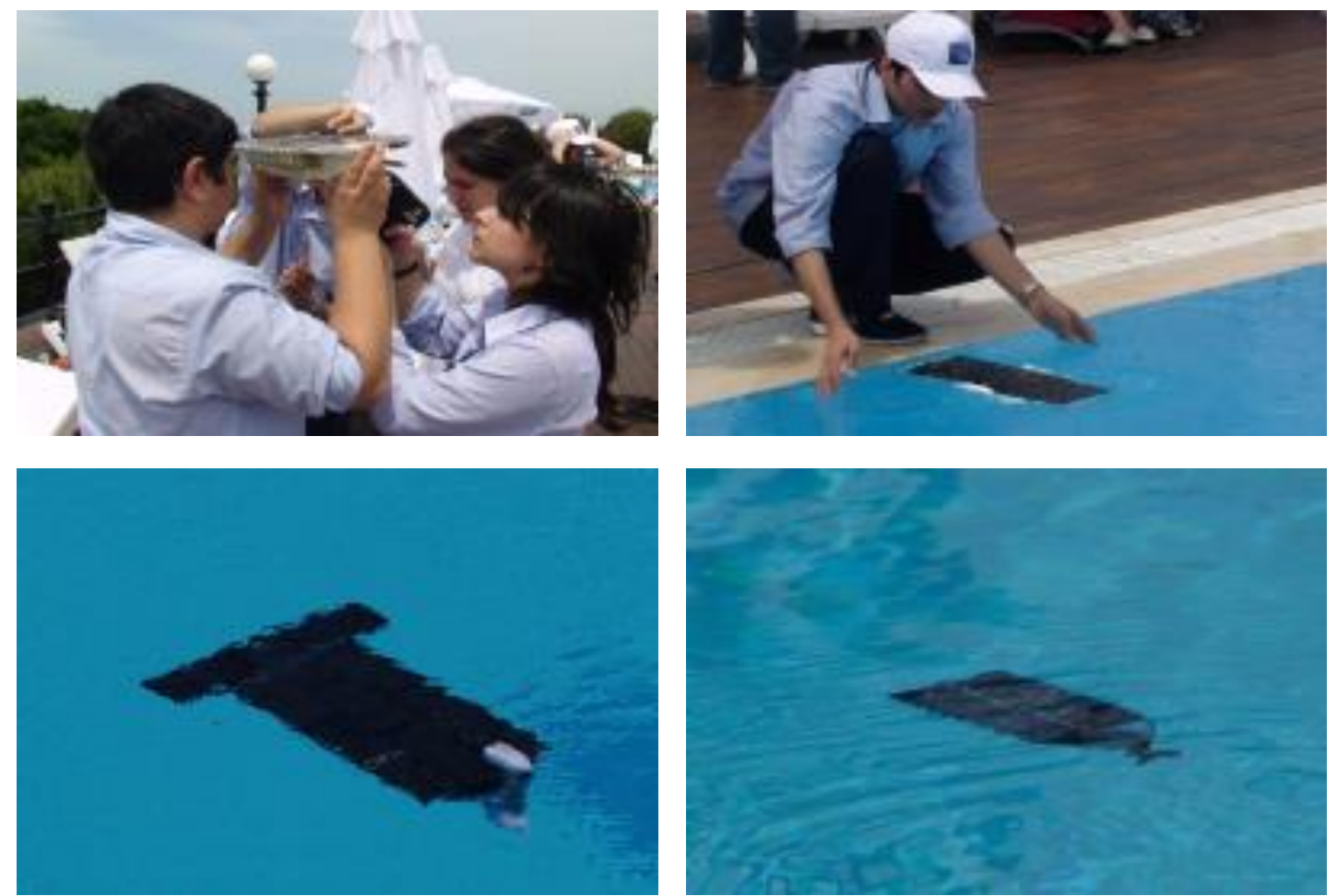

Figure 5. Photos from the SOPMOVER submarine organized in 2010.

Proc. of SPIE Vol. 9188 91880S-4 
The SOPMOVER underwater rower was organized in 2011 at the Koç University open swimming pool. This race was the sixth in the series with high school students participating.
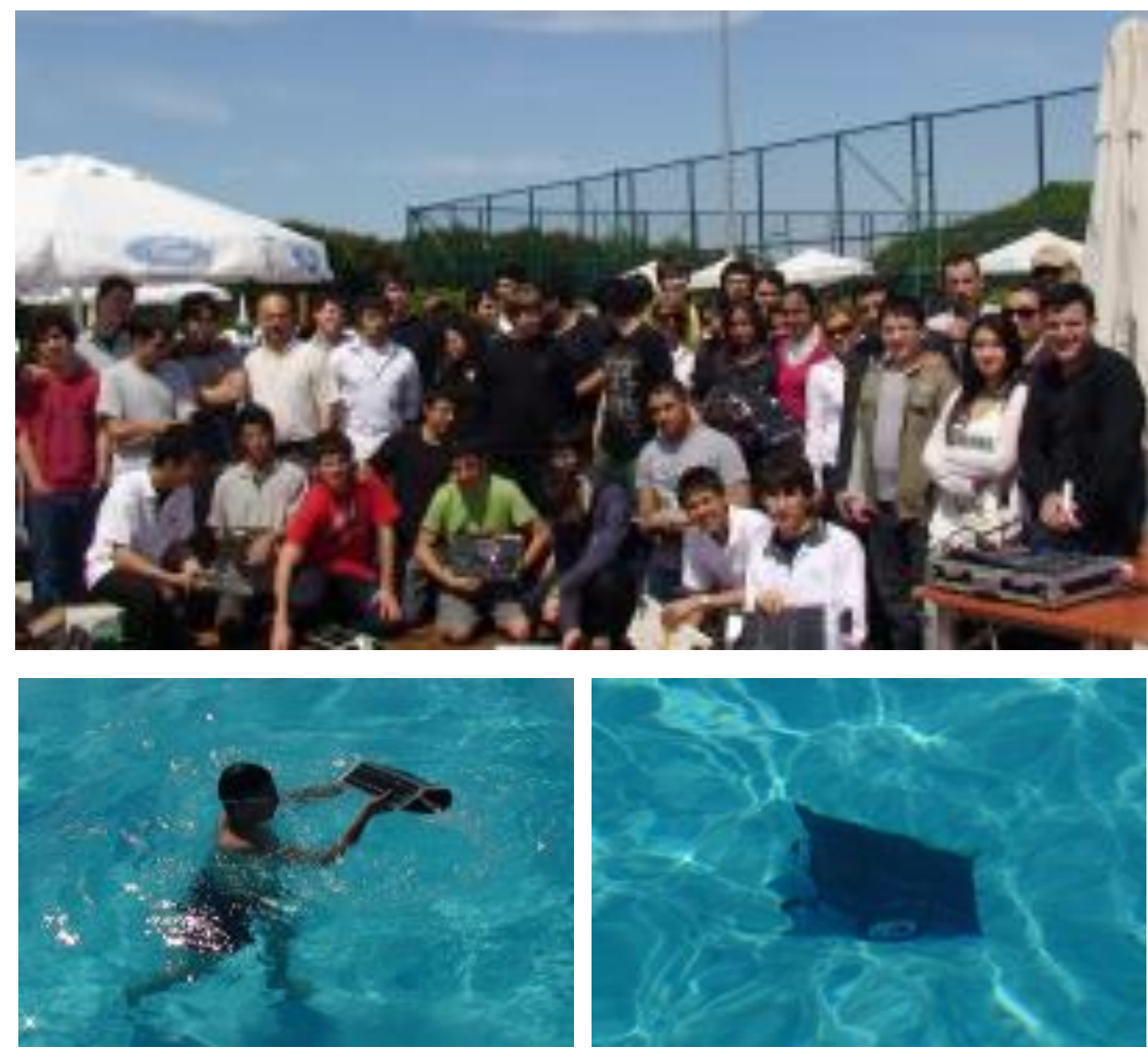

Figure 6. Photos from the SOPMOVER underwater rower organized in 2011.

The SOPMOVER amphibian was organized in 2012 at the Koç University open swimming pool. This race was the seventh in the series with high school students participating.
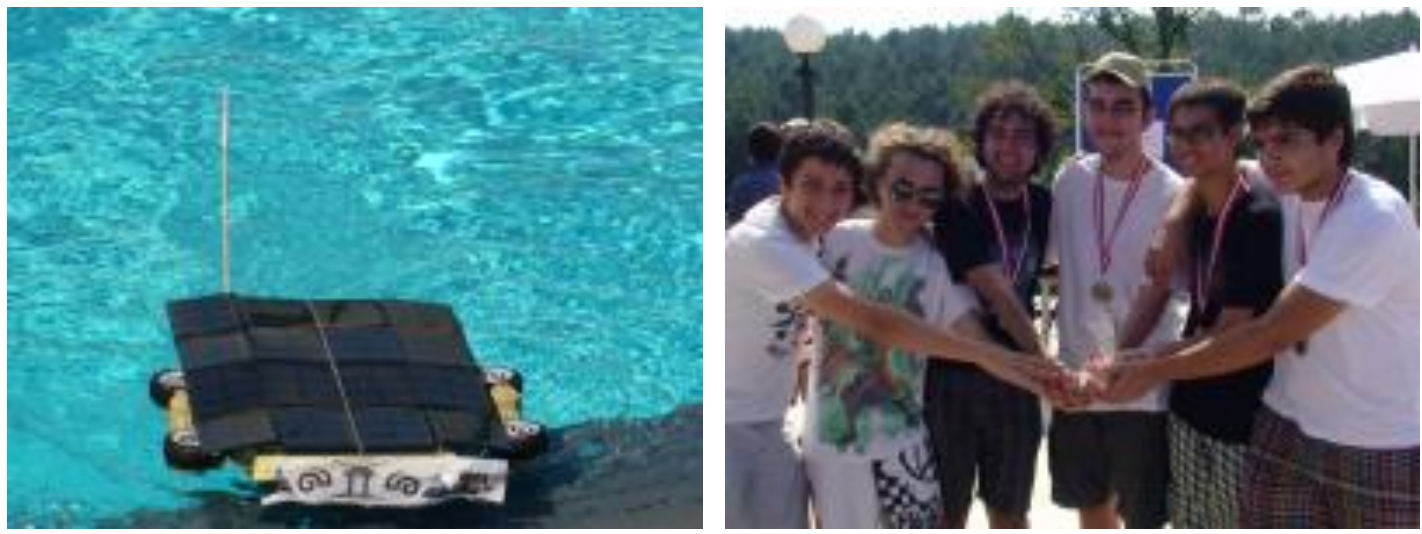

Figure 7(a). Photos from the SOPMOVER amphibian organized in 2012.

Proc. of SPIE Vol. 9188 91880S-5 


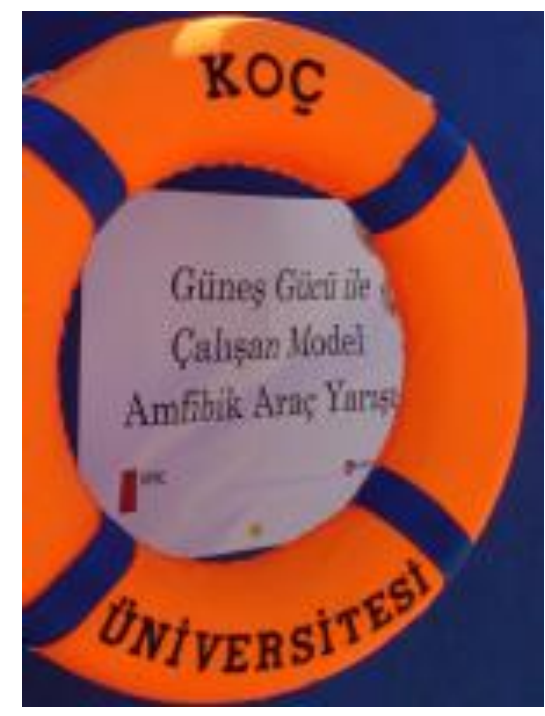

Figure 7(b). Photos from the SOPMOVER amphibian organized in 2012.

The SOPMOVER glider was organized in 2013 at the Koç University College of Sciences courtyard. This race was the eight in the series with high school students participating.
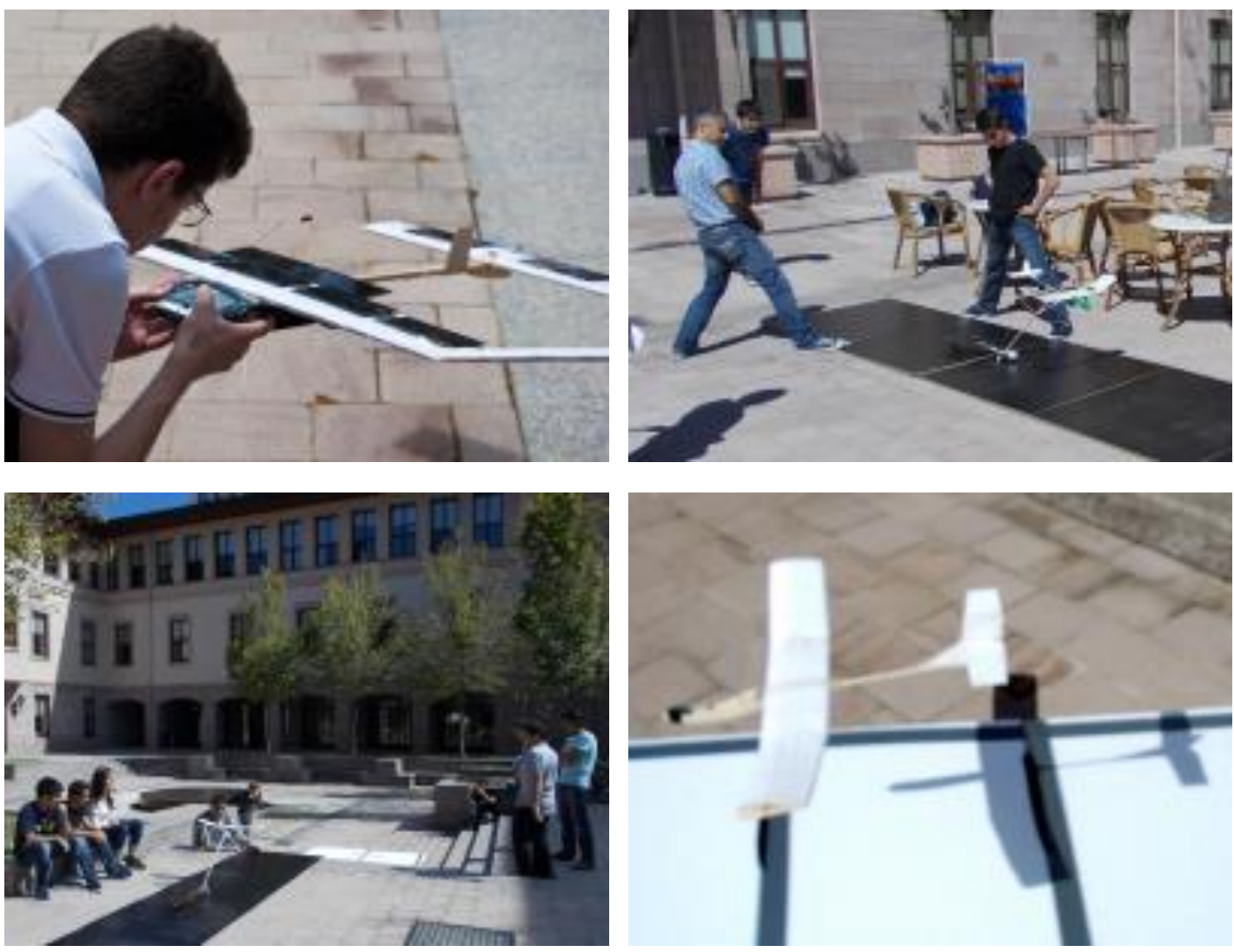

Figure 8. Photos from the SOPMOVER glider organized in 2013. 
As in all the previous solar races, our chapter member students first contacted a number of high schools in and around the city of Istanbul, promoted the race to students and their teachers and introduced the concept of the race. Then the model vehicle parts and solar cells including the race rules were forwarded to the participating student teams. The students had at least a month to build their own SOPMOVER glider at their school. Our chapter members regularly gave the teams feedback on their vehicle during this period. Most teams had difficulties in lowering the mass of their vehicle and making it more aerodynamic. The limiting factor of the solar panel efficiency was another challenging issue. Finally in a one day event all teams visited Koç University to race with their vehicles. Technical, logistic and social teams formed by our chapter member students gave the necessary support to the participants during the race. The participating teams powered their gliders in a 7 meters long runway to have them land as further away as possible in the landing platform, which was 0.7 meters lower than the runway. The best team successfully glided their vehicle 6.5 meters before landing in the lower platform. Members of the first three teams received awards and all students received a participant medal with Koç University SPIE student Chapter Logo on it. This activity attracted around 35 students.

\section{ACKNOWLEDGMENTS}

We would like to acknowledge the partial support and organization of these wonderful SOPMOVER events over the years by Koç University, SPIE, OSA, Smartkids, Darüşşafaka Gymnasium, and Domino's Pizza. Finally, we would like to acknowledge the efforts and enthusiasm of hundreds of volunteers, such as administrators, professors, teachers, students, mentors, parents, and families from Koç University, and from local and visiting K-12 schools, without which none of these photonics outreach events would have been possible.

\section{REFERENCES}

1. firstlegoleague.org

2. worldsolarchallenge.org 